\title{
HIV risk behaviours and factors affecting the use of condoms among men who have sex with men (MSM) in selected districts of Sri Lanka; A baseline cross sectional survey
}

\author{
Senadhira SDKP ${ }^{1}$, Suchira Suranga $\mathbf{M}^{1}$, Rajakaruna RMDK ${ }^{1}$, Abeykoon $A^{2}$, \\ ManathungeAKA ${ }^{3}$, Karawita $\mathbf{D A}^{3}$
}

\begin{abstract}
Introduction:

In the background of rising HIV prevalence patterns among $\operatorname{MSM}(0.0 \%$ in $2007,0.5 \%$ in 2008 and $0.9 \%$ in 2011) and relatively high estimated number of MSM $(32,796)$, it is important to scale up the reach and coverage of MSM in order to halt and reverse possible new HIV infections.
\end{abstract}

\section{Objective:}

The main objective of this study was to identify HIV risk behaviours and factors affecting the use of condoms among MSM in selected districts

\section{Method:}

Cross sectional descriptive study design was used to collect data from 961 respondents recruited by snow ball samplings in the selected five districts. Questionnaire was administered through peer leaders of MSM.

\section{Results:}

The mean age of the sample was 30.4 years (range 16-81 years, SD 9.26 years). Almost half of them were urban dwellers $(49.4 \%)$. The proportion of bridging population (males to females) was $31 \%$. Nearly $5 \%$ of them were male sex workers. The average male partner exchange rate in the previous month was 9 ( 7 local and 2 foreign). The proportion of penetrative and receptive anal sex during last month was $23 \%$ and $21 \%$. Condom use at last sex was
$40 \%$. In the multivariate analysis, those who are having receptive anal sex and who have taken treatment for STIs are more likely to use condoms.

\section{Conclusions:}

MSM in the sample have high to moderate rate of male partner exchange with less consistent condom use $(40 \%)$ indicating a substantial risk for HIV. MSM who are having receptive anal sex and who have taken treatment for STIs are more likely to use condoms

\section{Key Words: -}

MSM, HIV and STI Prevention, Sexual Practices, Condom

\section{Introduction}

Sri Lanka is an island near the southern tip of India. Its land extent is $65,000 \mathrm{~km}^{2}$ and having a population of nearly 21 million. (1) HIV prevalence in the country is less than $0.1 \%$ in the general population (2) and none of the high risk sub populations exceeds the prevalence of $1 \%$. Therefore, in epidemiological terms, the country is a low prevalent country since the first case of HIV infection identified in 1987 (2). The estimated number of adults and children living with HIV in Sri Lanka is 4200 for the year 2011. As of end second quarter 2013, a total of 1739 cases reported to the National STD/AIDS Control

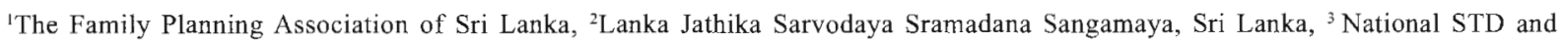
AIDS Control Program, Sri Lanka

Corresponding author: Senadhira SDKP, Email - kalhara@fpasrilanka.org
} 
Programme (NSACP) since the first local case detected in 1987. (2) However, the country cannot be complacent about the numbers because, Sri Lanka is one of the few countries where the number of new infections is on the rise in the South East Asia (3). The estimated rise of new infections from 2001 to 2011 was $70 \%$ in Sri Lanka (3). HIV surveillance system of the NSACP is constantly looking at some of key populations for possible outbreak of HIV since the first round of HIV sentinel survey carried out in 1990. (2) HIV prevalence pattern among MSM has gone up from $0.0 \%$ in 2007 to $0.5 \%$ in 2009 and further it has gone up to $0.9 \%$ in 2011 . The mapping and size estimation study carried out in 2009/10 revealed that the estimated number of MSM in the country was $31,000(24,000-37,000)$.

In this background, this study was conducted from June to August 2012 as a baseline survey of the Global Fund - Round 9 HIV prevention programme which is to be implemented targeting most at risk populations (MARP) for HIV prevention in Sri Lanka especially female sex workers (FSW), men who have sex with men (MSM), beach boys (BB) and drug users (DU). The main objectives of this study are to identify HIV risk behaviours and practices among MSM in selected districts and to identify factors affecting the use of condoms.

\section{Method}

Among 25 districts of the country five districts (Anuradhapura, Colombo, Galle, Gampaha and Kalutara districts) were purposely selected for this study as they were the selected districts to conduct the project activities under the HIV component of the Global Fund to fight AIDS, Tuberculosis and Malaria (GFATM) grant round 9 phase I, aligned with national strategic plan for HIV and STI control in Sri Lanka. From the selected areas of the project a total of 961 MSM were recruited as the sample. District level sample size was determined considering the relative proportions of the male population of each district (table 1). Snowball sampling technique with multiple district level seeds was used to enroll the potential participants.

Data were collected by using an interviewer administered, standardized questionnaire which was pretested for clarity, ambiguity, timing and sequence of questioning. Questionnaires were administered through selected MSM in each district as peer educators (PE) of the project. Total of 100 peer educators (Anuradhapura-20, Colombo-30, Galle-15, Gampaha-20 and Kalutara-15) were specially trained for the baseline data collection process and their activities were supervised by another seven (7) field supervisors.

Table 1: Sample sizes and percent of sample sizes taken from each selected districts

\begin{tabular}{|l|l|l|}
\hline Districts selected for sampling & Sample size & Sample as percent of total \\
\hline Anuradhapura & 194 & $20.2 \%$ \\
Colombo & 277 & $28.9 \%$ \\
Galle & 145 & $15.1 \%$ \\
Gampaha & 209 & $21.8 \%$ \\
Kalutara & 135 & $14 \%$ \\
Total sample size & 961 & 100 \\
\hline
\end{tabular}


The peer educators were clearly explained to provide adequate information on the purpose, confidentiality and anonymity of data and participation voluntarism before getting their consent for the study. After taking the respondents consent, the data were collected and recorded on the questionnaires which were later checked by the field supervisors for clarity and completeness.

\section{Data Analysis}

The collected data was primarily analyzed using the Microsoft excel software in order to arrange them in a meaningful way. Then SPSS and STATA; two statistical software were used to perform statistical analysis. The socioeconomic demographic data of the respondents were scientifically analyze $\mathrm{d}$ with respect to the respondents' status of condom usage. The parametric statistical methods such as t-test, Chisquire test and the logistic regression were used for the analysis.

\section{Results}

\section{Socio-demographic characteristics}

The socio-demographic characteristics of the sample shows that majority of respondents were in the age category of $\geq 25$ years $(71 \%$ ) while the $29 \%$ were in the less than 25 years age group. The mean age of the sample was 30.4 years (range 16-18 years, $\mathrm{SD}=9.26$ years $)$. Almost half of them were urban dwellers $(49.4 \%)$. Heterosexual marriages were present in $33 \%$ of the sample showing the proportion of MSM who could possibly transmit infection to the

Table 2: Descriptive statistics - socio-demographic characteristics of respondents

\begin{tabular}{|c|c|c|c|c|}
\hline Category & Category & & Count & Percent \\
\hline \multirow[t]{5}{*}{ Age } & $<14$ years & & 0 & $0 \%$ \\
\hline & $14-24$ & & 278 & $28.9 \%$ \\
\hline & $25-59$ & & 676 & $70.3 \%$ \\
\hline & $>59$ & & 7 & $0.7 \%$ \\
\hline & & Total & 961 & $100 \%$ \\
\hline \multirow[t]{4}{*}{ Geography } & Rural & & 315 & $16.1 \%$ \\
\hline & Semi urban & & 330 & $34.4 \%$ \\
\hline & Urban & & 316 & $49.4 \%$ \\
\hline & & Total & 961 & $100 \%$ \\
\hline \multirow[t]{5}{*}{ Marital status } & Never married & & 606 & $65.93 \%$ \\
\hline & Married & & 208 & $24.4 \%$ \\
\hline & living together & & 58 & $6.14 \%$ \\
\hline & Divorced & & 23 & $2.5 \%$ \\
\hline & & Total & 895 & $100 \%$ \\
\hline \multirow[t]{6}{*}{ Level of education } & No education & & 19 & $2.5 \%$ \\
\hline & Up to grade 5 & & 28 & $3.1 \%$ \\
\hline & Up to grade 8 & & 75 & $8.3 \%$ \\
\hline & $\mathrm{Up}$ to $\mathrm{O} / \mathrm{L}$ & & 393 & $43 \%$ \\
\hline & $\mathrm{A} / \mathrm{L}$ and above & & 394 & $43 \%$ \\
\hline & & Total & 909 & $100 \%$ \\
\hline \multirow[t]{5}{*}{ Occupation } & Labourer/driver & & 217 & $53.58 \%$ \\
\hline & Unemployed & & 85 & $20.98 \%$ \\
\hline & Beauty culture/saloon & & 70 & $17.28 \%$ \\
\hline & Commercial sex work & & 33 & $8.14 \%$ \\
\hline & & Total & 405 & $100 \%$ \\
\hline
\end{tabular}


general population (bridging population of MSM). Nearly half of them were educated up to the level of General Certificate of Education (Advanced level) which is equal to 13 years of school education. One of the important findings of the study is that, 33 respondents $(4.93 \%)$ have indicated the commercial sex work as their occupation. Table 2 explains the descriptive statistics of the sample.

\section{The Durations of the Sexual Behavior}

The duration of the respondents' sexual behavior as MSM, ranges from $<1$ year to 60 years. One fourth $(25.09 \%)$ of respondents had less than 6 years of MSM behaviours while almost another one forth (23.27\%) had 6-10 years of experience. Overall, majority $(71 \%)$ of them had less 15 years of experience as an MSM (Table 3).

\section{Type and number of sex partners}

Majority of them (63\%) had sex only with male partners while $31 \%$ of them had sex with both males and females during the last month representing the proportion of bridging population within the sample. The average number of local (Sri Lankan) and foreign male partners during the last month was 7 (range 084 ) and 2 (range $0-10$ ) respectively while the same figure for female partners was 2 (range 0-15). Distribution of number of partners according to the category of numbers is mentioned in the table 3 . This study reveals that around $21 \%$ of the respondents have had only receptive anal sex during the last month. Another $23 \%$ of the respondents have had only penetrative anal sex during the last month. More than one third of (39\%) of the respondents have had both receptive and penetrative sex, while remaining portion of respondents have had no any kind of anal sexual encounters during the last month (Table 3 ).

\section{Condom use}

Condom use at last sex with males was $40 \%$. More than three fourth $(76.88 \%)$ of the respondents had mentioned that either they did not use a condom during the last sex with a female or they have never had sex with a female. These findings reveal that majority MSM (60\%) do not have consistent condom use.

Table 3: Sexual behavior characteristics

\begin{tabular}{|c|c|c|c|c|}
\hline Category & Category & & Count & Percent \\
\hline \multirow[t]{6}{*}{ Duration of MSM behavior } & $<6$ years & & 221 & $25.1 \%$ \\
\hline & $6-10$ years & & 205 & $23.3 \%$ \\
\hline & $11-15$ years & & 200 & $22.7 \%$ \\
\hline & $16-20$ years & & 138 & $15.7 \%$ \\
\hline & $>20$ years & & 117 & $13.3 \%$ \\
\hline & & Total & 881 & $100 \%$ \\
\hline \multirow{5}{*}{$\begin{array}{l}\text { Sexual encounters during } \\
\text { last month }\end{array}$} & No & & 46 & $5 \%$ \\
\hline & only with males & & 576 & $63.1 \%$ \\
\hline & both males and females & & 283 & $31 \%$ \\
\hline & only with females & & 08 & $0.9 \%$ \\
\hline & & Total & 913 & $100 \%$ \\
\hline \multirow{6}{*}{$\begin{array}{l}\text { Number of male sexual } \\
\text { partners during the last month }\end{array}$} & No & & 45 & $4.9 \%$ \\
\hline & 1 & & 64 & $7.1 \%$ \\
\hline & 2 to 5 & & 384 & $42.5 \%$ \\
\hline & 6 to 10 & & 254 & $28.1 \%$ \\
\hline & above 10 & & 157 & $17.4 \%$ \\
\hline & & Total & 904 & $100 \%$ \\
\hline
\end{tabular}




\begin{tabular}{|c|c|c|c|c|}
\hline \multirow{6}{*}{$\begin{array}{l}\text { Number of foreign male sexual } \\
\text { partners during last month }\end{array}$} & No & & 848 & $93.8 \%$ \\
\hline & 1 & & 25 & $2.8 \%$ \\
\hline & 2 to 5 & & 28 & $3.1 \%$ \\
\hline & 6 to 10 & & 3 & $0.3 \%$ \\
\hline & above 10 & & 0 & $0.0 \%$ \\
\hline & & Total & 904 & $100 \%$ \\
\hline \multirow{6}{*}{$\begin{array}{l}\text { Number of female sexual } \\
\text { partners during the last month }\end{array}$} & No & & 622 & $68.1 \%$ \\
\hline & 1 & & 157 & $17.2 \%$ \\
\hline & 2 to 5 & & 116 & $12.7 \%$ \\
\hline & 6 to 10 & & 14 & $1.5 \%$ \\
\hline & above 10 & & 4 & $0.4 \%$ \\
\hline & & Total & 913 & \\
\hline \multirow{6}{*}{$\begin{array}{l}\text { Number of foreign female } \\
\text { sexual partners during last month }\end{array}$} & No & & 890 & $97.5 \%$ \\
\hline & 1 & & 8 & $0.9 \%$ \\
\hline & 2 to 5 & & 15 & $1.6 \%$ \\
\hline & 6 to 10 & & 0 & $0.0 \%$ \\
\hline & above 10 & & 0 & $0.0 \%$ \\
\hline & & Total & 913 & $100 \%$ \\
\hline \multirow{6}{*}{$\begin{array}{l}\text { Type of anal sex had during } \\
\text { the last month }\end{array}$} & only receptive anal sex & & 192 & $21 \%$ \\
\hline & only penetrative anal sex & & 215 & $23 \%$ \\
\hline & both receptive and & & & \\
\hline & penetrative anal sex & & 360 & $39 \%$ \\
\hline & No anal sex encounters & & 146 & $15 \%$ \\
\hline & & Total & 913 & $100 \%$ \\
\hline \multirow[t]{2}{*}{ Condom use at last sex with males } & did not use & & 518 & $59.9 \%$ \\
\hline & used a condom & & 347 & $40.1 \%$ \\
\hline \multirow[t]{2}{*}{$\begin{array}{l}\text { Condom use at last sex with } \\
\text { females }\end{array}$} & $\begin{array}{l}\text { did not use a condom or } \\
\text { never had sex with females }\end{array}$ & & 665 & $76.9 \%$ \\
\hline & used a condom & & 248 & 28.7 \\
\hline
\end{tabular}

\section{Characteristics of condom users and non-users}

There is no significant relationship between condom users and non-users in relation to age, number of male or female partners. Those who have longer duration of MSM behavior show a tendency to use condoms. It shows that years of school education among MSM has negative result on use of condoms (table 4a) 
Table 4a: Comparison of variables between condom users and non-users for the difference

\begin{tabular}{|llll|}
\hline Category & $\begin{array}{l}\text { Condom users at last } \\
\text { sex with males; mean; } \\
(95 \% \mathrm{CI})(\mathrm{n}=347)\end{array}$ & $\begin{array}{l}\text { Condom non users at last } \\
\text { sex with males; mean } \\
;(95 \% \mathrm{CI})(\mathrm{n}=566)\end{array}$ & Significane \\
\hline Mean age in years & $31.0(30.1-31.9)$ & $30.0(29.3-30.7)$ & $\mathrm{p}=0.1018$ \\
\hline $\begin{array}{l}\text { Duration of MSM behaviour } \\
\text { in years }\end{array}$ & $13.2(12.2-14.1)$ & $11.8(11.1-12.5)$ & $\mathrm{p}=0.0186^{*}$ \\
\hline Years of education & $10.6(10.2-10.9)$ & $11.6(11.34-11.8)$ & $\mathrm{p}=0.0001^{*}$ \\
\hline No. of male sexual partners & $9.1(7.1-11.2)$ & $6.6(6.0-7.3)$ & $\mathrm{p}=0.065$ \\
\hline No. female sexual partners & $0.7(0.5-0.9)$ & $0.7(0.5-0.8)$ & $\mathrm{p}=0.6423$ \\
\hline
\end{tabular}

* significant by t-test at $a=0.05$

In order to find out the relationship between the condom usage with the, geographical location, extent of urbanization, marital status, number of penetrative anal sex, number of receptive anal sex, status of taking treatment for STI, the Pearson chi squired test

was performed for each of above variables separately. The results reveal that all above variables except number of penetrative anal sex during the last month has a relationship with the usage of condoms during the sex with males.

Table 4b: Comparison of variables between condom users and non-users for the association

\begin{tabular}{|c|c|c|c|c|}
\hline \multirow[t]{2}{*}{ Variables } & \multirow{2}{*}{$\begin{array}{l}\text { Value } \\
\text { categories }\end{array}$} & \multirow{2}{*}{$\begin{array}{l}\text { Condom users } \\
\text { at last sex with } \\
\text { males; count } \\
\text { (percent) }\end{array}$} & \multicolumn{2}{|c|}{$\begin{array}{l}\text { Condom non users significance } \\
\text { at last sex with } \\
\text { males; count } \\
\text { (percent) }\end{array}$} \\
\hline & & & $113(76 \%)$ & Pearson chi2(4) \\
\hline & Colombo & $143(52 \%)$ & $131(48 \%)$ & $=46.3232$ \\
\hline & Galle & $43(29 \%)$ & $109(31 \%)$ & $\mathrm{P}=0.000^{* *}$ \\
\hline & Gampaha & $73(36 \%)$ & $132(34 \%)$ & \\
\hline & Kalutara & $53(40 \%)$ & $81(60 \%)$ & \\
\hline & Total & $347(100 \%)$ & $566(100 \%)$ & \\
\hline \multirow[t]{4}{*}{ Extent of Urbanization } & Rural & $86(30 \%)$ & $200(70 \%)$ & Pearson chi2(2) \\
\hline & Semi-Urban & $136(42 \%)$ & $188(58 \%)$ & $=9.9759$ \\
\hline & Urban & $125(41 \%)$ & $178(59 \%)$ & $\mathrm{P}=0.007 * *$ \\
\hline & Total & $347(100 \%)$ & $561(100 \%)$ & \\
\hline \multirow[t]{6}{*}{ Marital status } & Married & $44(31 \%)$ & $141(69 \%)$ & Pearson chi2(4) \\
\hline & Unmarried & $222(36 \%)$ & $384(74 \%)$ & $=32.7941 \mathrm{P}$ \\
\hline & Living together & $40(68 \%$ & $18(32 \%)$ & $=0.000 * *$ \\
\hline & Divorced & $10(43 \%)$ & $13(57 \%)$ & \\
\hline & Widow & $4(67 \%)$ & $2(33 \%)$ & \\
\hline & Total & $320(100 \%)$ & $558(100 \%)$ & \\
\hline \multirow{5}{*}{$\begin{array}{l}\text { Number of penetrative } \\
\text { anal sex during last } \\
\text { month }\end{array}$} & None & $132(39 \%)$ & $206(61 \%)$ & Pearson chi2(3) \\
\hline & 01 to 06 & $137(36 \%)$ & $243(64 \%)$ & $=0.8785$ \\
\hline & 07 to 10 & $44(40 \%)$ & $65(60 \%)$ & $\mathrm{P}=0.831$ \\
\hline & Above 10 & $34(40 \%)$ & $52(60 \%)$ & \\
\hline & Total & $347(100 \%)$ & $566(100 \%)$ & \\
\hline
\end{tabular}




\begin{tabular}{|lrrrl|}
\hline Number of receptive & None & $104(29 \%)$ & $257(71 \%)$ & Pearson chi2(3) \\
anal sex during last & 01 to 06 & $119(39 \%)$ & $187(61 \%)$ & $=16.1333$ \\
month & 07 to 10 & $49(45 \%)$ & $59(55 \%)$ & $\mathrm{P}=0.001^{* *}$ \\
& Above 10 & $75(54 \%)$ & $63(46 \%)$ & \\
& Total & $347(100 \%)$ & $566(100 \%)$ & \\
\hline Number of MSM & None & $194(28 \%)$ & $505(72 \%)$ & Pearson chi2(1) \\
tested for HIV during & Yes & $153(72 \%)$ & $61(28 \%)$ & $=126.5161$ \\
last 12 months & Total & $347(100 \%)$ & $566(100 \%)$ & $\mathrm{P}=0.000^{* *}$ \\
\hline
\end{tabular}

Further, a logistic regression was performed to identify the factors affecting the status of condom usage by the respondents. As shown in the table 05, the results of the logistic regression indicated that the level of education, number of receptive anal sexual encounters during the last month, status of taking treatment for a STI (whether the respondent had taken treatment for STI during their lifetime), had a statistically significant effect on status of condom usage $(\mathrm{CI}=95 \%)$. Among those three factors level of education indicated a negative effect on the usage of condoms while other two factors indicated a positive effect on the condom usage. Other factors such as extent of urbanization, district, age, marital status, duration in MSM behavior, number of male sexual partners, number of female sexual partners, number of penetrative anal sexual encounters, did not have a statistically significant effect on status of condom use $(\mathrm{CI}=95 \%)$.

\section{Discussion}

The sample shows that majority of respondents (71\%) were in the age category of $\geq 25$ years (mean age 30.4 years, $\mathrm{SD}=9.26$ years). The ages of majority of respondents in various MSMs studied carried out in Sri Lanka were in their twenties or early thirties (4) (5) (6). This may be due to the true picture or sampling error because of non-probability sampling techniques used in this type of hidden populations.

In this study, the average male partner exchange rate during the last month was 9 , while the same figure for female was 2. In 2006-2007 Behavioural Surveillence Survey (BSS), on average, respondents had 0.9 regular male partners and almost 8.8 non regular partners in the previous year (as calculated for the full sample). $2008 \mathrm{MSM}$ study-Anuradhapura, showed that the average male partner exchange rate

Table 5: Results of the logistic regression for status of condom usage

\begin{tabular}{llrr}
\hline Logistic regression & Number of obs & 8 & 892 \\
& LR chi2(12) & 64.13 \\
& Prob > chi2 & $=$ & 0.0000 \\
Log 1ikelihood $=-559.81013$ & Pseudo R2 & $=$ & 0.0542
\end{tabular}

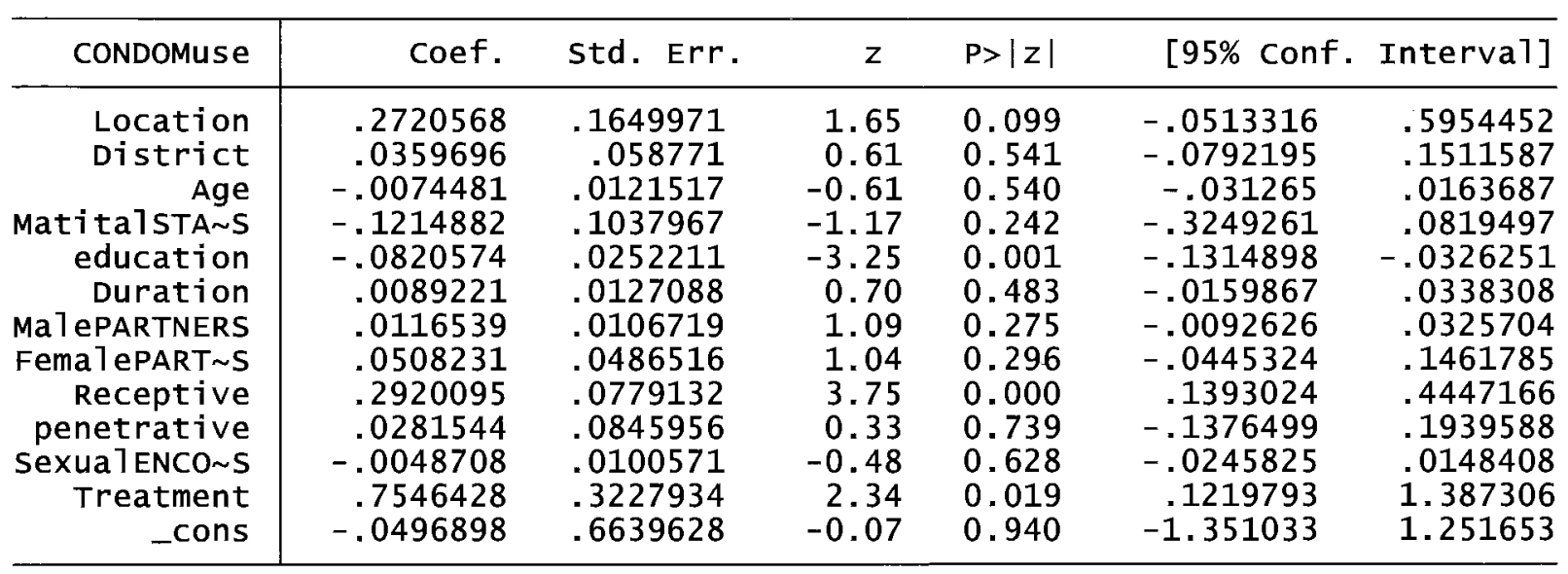


in the previous year was 7 ( 0.26 regular male partners and 6.68 non-regular male partners) and the average female partner exchange rate per year was $4(0.39$ regular female partners and 3.5 non-regular female partners) (4) In India, the mean number of commercial partners of MSM ranged from 3.6-25.2 in the past six months, In Indonesia, the number of male partners of MSM varied from 2-10 (7). This study shows relatively high rate of partner change. This may be due to the fact that the sample represents high risk MSMs and/or the presence of $5 \%$ of male commercial sex workers in the sample.

It is mentioned in the report of the Commission on AIDS in Asia, that about $60 \%$ of most-at-risk populations need to adopt safer behaviours, if HIV epidemics are to be reversed. To achieve that level of behavior change, service coverage has to reach at least $80 \%$. (8) According to this baseline study, the condom use at last sex was $40 \%$ which need to be improved at least over $60 \%$ to reduce the rate of new infections. On the other hand, coverage of reach is also not adequate when compared with the moving estimates of MSMs in the country. One third to two third of MSM across South-East Asia reported not using condoms during the last episode of anal sex with a male partner. In 2010 , according to the country reports, condom use at last sex with a male partner varied from $22 \%$ in Bangladesh to $82 \%$ in Myanmar, $88 \%$ in Nepal, $50 \%$ in Sri Lanka, $65 \%$ in Thailand and $52 \%$ in Timor-Leste (7) In South-East Asia, although many countries in the region are focusing on increasing the coverage of interventions for safer sexual behaviours, the magnitude of the current prevention programmes for MSM is highly inadequate. The reported median regional prevention coverage was $49 \%$ for MSM while the global median coverage was at $58 \%$ (7) It is recommended by the team of external review of the national response to HIV in Sri Lanka that the country should use the financial resources from the Global Fund grants to continue and increase reach and coverage of MSM in the country (9)
This study also reveals that the proportion of penetrative and receptive anal sex was $23 \%$ and $21 \%$ during the last month. More than one third of $(39 \%)$ of the respondents have had both receptive and penetrative sex, while remaining portion of respondents have had no anal sexual encounters during the last month. In 2006/07 BSS, the average number of partners for insertive anal sex was 11.7 and for receptive anal intercourse 12.5 in the last year

Proportion of bridging population (males to females) was $31 \%$ in this baseline study during the last month. In the BSS 2006-2007, 23\% of MSM had sexual intercourse with a woman in the previous year which suggest an additional risk of transmission to other populations

In this baseline study, when the characteristics of condom users and non-users at last sex were compared in the multivariate analysis, those who are having receptive anal sex and who have taken treatment for STIs were more likely to use condoms. But it is questionable that the higher level of education indicated a negative effect on the usage of condoms which needed to be tested further for the consistency of the finding

\section{Conclusions}

MSM in the sample had relatively high to moderate rate of male partner exchange with low rate of condom use at last sex (40\%) indicating a substantial HIV risk behaviours. The presence of considerable proportion of bridging population (31\%) further suggests an additional risk of cross-population transmission. The level of condom use was inadequate to reverse a possible increase in new infections among MSM. It has been shown in this study that the experience of an STI is one of the most influencing factors for them to use a condom which is a too late situation as far as HIV prevention is concerned. MSM who are having receptive anal sex has relatively high tendency to use condoms probably due to perceived risk. However, in this study, a higher level of education indicated a negative effect on the usage of 
condoms which needed to be tested further for the consistency of the finding.

\section{Acknowledgements}

Heart to Heart Lanka organization, Colombo, Rajarata Gemivpahana, Anuradhapura, Saviya Development Foundation, Galle

\section{Conflict of interest}

No conflict of interest

\section{Funding}

GFATM Round-9 Project (Phase - 01)

\section{References:}

1. Depatment of Census and Statistics, Sri Lanka.[Online]. [cited 2013 August 06.Available from:http://www.statistics.lk

2. National STD/AIDS Control Programme.National STD/AIDS Control Programme [Online] [cited 2013 August 06. avilable from : http://www.aidscontrol.gov.lk

\section{UNAIDS.UNAIDS World AIDS Day}

Report.Geneva: UNAIDS; 2012.

4. Karawita A. Risk Level among male homosexuals in Sri Lanka Dutschland : lap Lambert Academic Publishing Gmbh \& Co.KG; 2011

5. Rewstorne P, Worth H.Sri Lanak Behavioural Surveillance, Colombo: National STD/AIDS Controal Programme, Ministery of Healthcare and Nutrition, 2006-2007

6. Ariyaratne KAM, Matthiew T. Knowledge attitudes and practice in the gay community, gay identyfied men, and men who have sex with men in Sri Lanka. Study Report.Colombo.Companions on a Journey; June 2007

7. Regional Office for South East-Asia .HIV AIDS in the South East Asia Region.Progress report
2011.World Health Organization, Regional Office for south east Asia ; 2011

Report No. : 978-92-9022-427-3

8. Commission on AIDS in Asia. Redefining AIDS in Asia, crafting an effective Responce. New Delhi; March 2008. Report No; 0-19-569636-0

9. ChanP-L, Loo V, Mangalika P,Mehera, Senavirathna R, Uhrig J. External revies of national responce to STI and HIV in Sri Lanka, Colombo National STD/AIDS Controal Programme, Ministry of Health,Sri Lanka; 2011

10 Karawita DA Mosses S, Emmanuanuel F, Shely I Edirisinha N Ariyarathna KAM, Ranathunga D Chawala R Nawaratne K. Mapping and size estimation of female sex workers and men who have sex with men in Sri Lanka.Sri Lanka Journal of venereology 2012 October; 3(1) 